\title{
BMJ Open Discrepancies in drug histories at admission to gastrointestinal surgery, internal medicine and geriatric hospital wards in Central Norway: a cross- sectional study
}

\author{
Janne Kutschera Sund, ${ }^{1,2}$ Olav Sletvold, ${ }^{3,4}$ Trude Cecilie Mellingsæter, ${ }^{5}$ \\ Randi Hukari, ${ }^{6}$ Torstein Hole, ${ }^{7,8}$ Per Einar Uggen, ${ }^{9}$ Petra Thiemann Vadset, ${ }^{7}$ \\ Olav Spigset ${ }^{1,5}$
}

To cite: Sund JK, Sletvold 0 , Mellingsæter TC, et al. Discrepancies in drug histories at admission to gastrointestinal surgery, internal medicine and geriatric hospital wards in Central Norway: a crosssectional study. BMJ Open 2017;7:e013427. doi:10.1136/ bmjopen-2016-013427

- Prepublication history for this paper is available online. To view these files, please visit the journal online (http://dx.doi. org/10.1136/bmjopen-2016013427).

Received 30 March 2017

Revised 8 July 2017

Accepted 9 August 2017

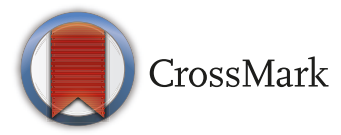

For numbered affiliations see end of article.

Correspondence to Janne Kutschera Sund; janne.k.sund@ntnu.no

\section{ABSTRACT}

Objectives To compare discrepancies in drug histories among patients acutely admitted to different hospital wards, classify the discrepancies according to their potential clinical impact and identify appropriate selection criteria for patients that should be subject to a detailed drug history at admission.

Design Cross-sectional study.

Setting Two gastrointestinal surgery wards and one geriatric ward at St Olav's University Hospital in Trondheim and two general internal medicine wards at Ålesund Hospital in Ålesund, Norway.

Participants All patients acutely admitted to these wards during a period of three months were asked to participate in the study. A total of 168 patients were included. For each patient, drug information available at admission was compared with information from drug lists obtained from the general practitioner and (if applicable) the home care services/the nursing home.

Primary and secondary outcome measures Number of patients with one or more discrepancies in their drug history. Type and clinical impact of the discrepancies found. Selection criteria for patients that should be subject to a detailed drug history.

Results In total, $83 \%$ had at least one discrepancy in their drug history. Omission of a drug accounted for $72 \%$ of the discrepancies, whereas a difference in dosing was the cause of the remaining $28 \%$. $9 \%$ of the discrepancies had the potential to cause severe harm or discomfort. We found no significant differences in the number of discrepancies between hospital wards, genders, ages or levels of care. Conclusions This study demonstrates the importance of collecting drug information from all available sources when a patient is admitted to hospital. As we found no significant differences in discrepancies between subgroups of patients, we suggest that medication reconciliation should be performed for all patients.

\section{INTRODUCTION}

An accurate drug history is an essential part of patient assessment at admission to hospital.
Strengths and limitations of this study

- This study was conducted in three different hospital settings with patients in a large range of ages and diseases.

- The use of a multidisciplinary expert group enhanced the understanding of the severity score classification and increased the conformity of the evaluations.

- Unfortunately, there is no 'golden standard' for the accurate drug list of a patient; in some cases, we were not able to identify the correct list.

- As this is a cross-sectional study, no follow-up data was available.

An erroneous drug history may result in failure to detect drug-related problems as the cause of hospital admission or lead to interrupted or inappropriate drug therapy during and after hospitalisation. Several studies have shown that errors in drug histories are frequent and clinically important. ${ }^{1-5}$ In a patient safety perspective, the primary goal is to identify and correct errors in the drug history sufficiently early to prevent any harm or discomfort to the patient. In addition, handling and correcting errors might cause an extra administrative workload.

Causes of errors in drug histories are complex and can principally be related to the healthcare personnel, the patient or the processes and systems involved. ${ }^{367}$ Medication reconciliation has been defined as 'A process of identifying the most accurate list of all medications a patient is takingincluding name, dosage, frequency and route-and using this list to provide correct medications for patients anywhere within the health care system. ${ }^{8}$ Medication reconciliation has been recommended by health 


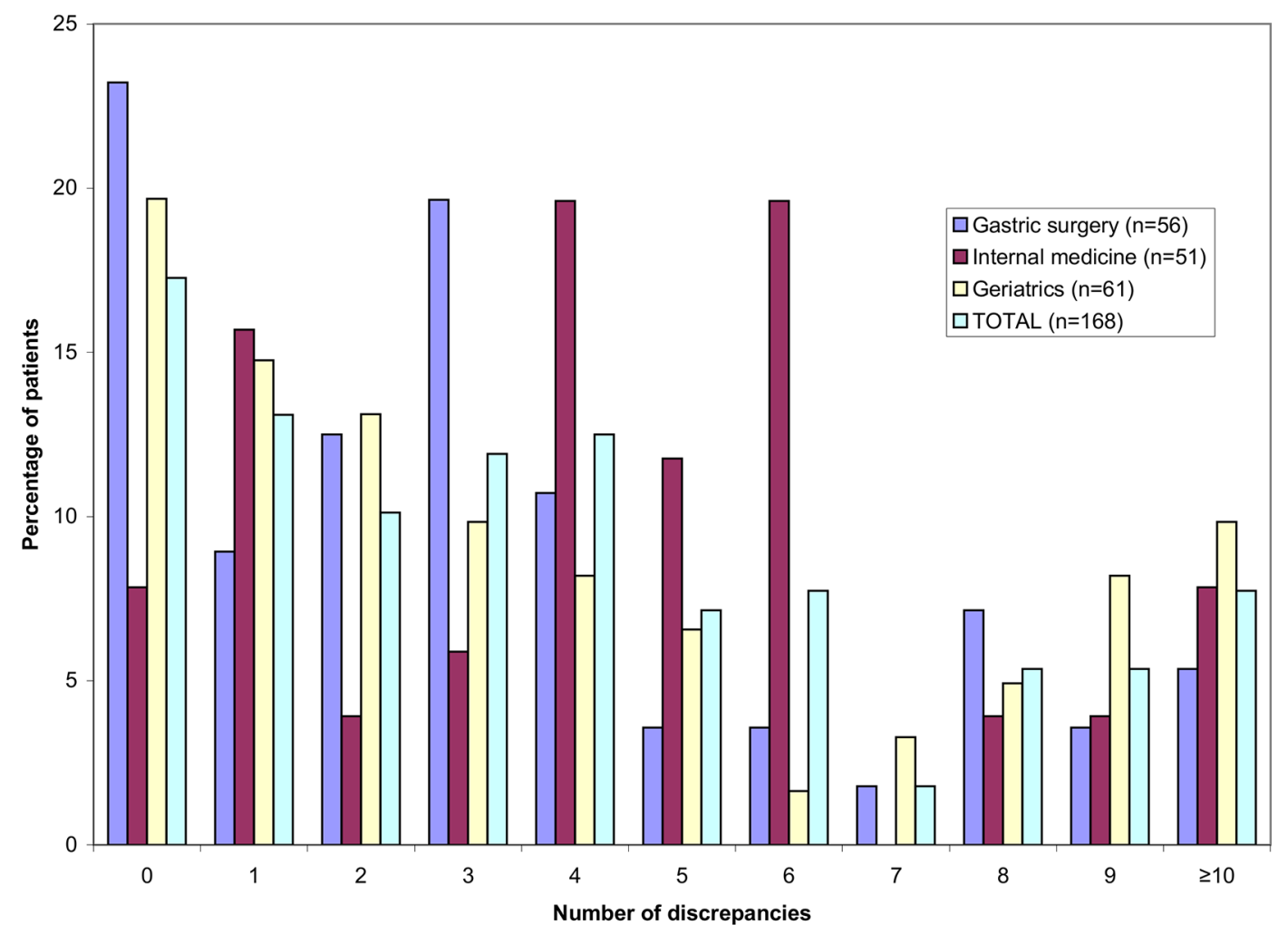

Figure 1 Distribution of patients according to the total number of discrepancies found when comparing the drug list from the hospital record with all other available sources of information.

authorities and patient safety organisations in several countries. $^{89}$

An American study from 2008 has shown that pharmacists appear to be better suited and more effective than physicians in obtaining drug histories, ${ }^{10}$ and a Belgian study published in 2010 demonstrates that pharmacists are especially suited to acquire and supervise accurate medication histories. ${ }^{11}$ Pharmacists in many countries have developed standardised procedures for obtaining complete drug histories, including systematic medication reconciliation. $^{3671112}$

Various factors have been associated with an increased risk of discrepancies in the drug history at admission to hospital including age, level of healthcare, number of drugs and diagnoses. ${ }^{3613}$ At present, results from studies aiming to identify factors predicting errors or discrepancies in drug histories are inconclusive and contradictory. ${ }^{2} 36713-15$ Owing to the limited resources usually available for performing quality controls of drug histories, developing appropriate selection criteria is of crucial importance.

Most previous studies in the area have included elderly patients in internal medicine wards in a single hospital. ${ }^{2} 3671516$ The results from these studies might not be representative for other patient populations. One study by Unroe et al from 2010 showed a significant difference in the proportion of patients with discrepancies on admission to hospital between patients admitted to cardiology service, general medicine and general surgery, $15 \%, 22 \%$ and $35 \%$, respectively. ${ }^{12}$
The aim of this study was to identify and compare discrepancies in drug histories among patients acutely admitted to various types of hospital wards, classify the discrepancies according to their potential clinical impact and identify appropriate selection criteria for patients that should be subject to detailed medication reconciliation.

\section{METHODS}

The study was conducted as a cross-sectional study in five different hospital wards-two gastrointestinal surgery wards at St Olav's University Hospital in Trondheim, Norway, two general internal medicine wards at Ålesund Hospital in Ålesund, Norway and one geriatric ward at St Olav's University Hospital. St Olav's is a large university hospital in the city of Trondheim, Central Norway, with 983 beds of which 48 are located in the gastrointestinal surgery wards and 15 in the geriatric ward. Ålesund Hospital is a secondary hospital covering the northern part of western Norway with approximately 270 beds, of which 48 are located in the two internal medicine wards. All patients acutely admitted to these wards during a period of 3 months were asked to participate in the study. The patients were informed both orally and in writing about the study and those giving their written informed consent were included in the study. The Regional Ethics Committee of Central Norway considered the study to be a quality-control study, and as such, the committee stated that no further approval was necessary. 
In Norway, there are several patient record systems both within primary care and within secondary care. These systems do not communicate with each other, and health professionals from primary and secondary care or even from different hospitals do not have access to each other's patient records. Therefore, the patients' medication lists were collected manually, and medication reconciliation was performed by a clinical pharmacist after admission to the wards. The patients' drug lists, as obtained by the doctor in charge at admission to hospital, were collected from the hospital records taken at admission. These lists are seen as the main source of information on which the doctor bases his prescribing in the drug chart. Information from the drug chart was not collected in this study. As soon as practically feasible after admission, the following efforts were taken to obtain supplementary drug information:

For patients living in their own homes, the patients' general practitioners (GP) were contacted by telephone to provide the latest medication records.

For patients living in their own homes receiving home care services and patients living in nursing homes, we contacted, in addition to the GP, also the caregivers by telephone, asking them to provide a copy of the patients' drug list. Drug information from the home care services and the nursing homes was classified together, since the patients in both cases did not handle their own drugs, but received their drugs from a nurse.

Age, gender, level of care before admission and data from all available drug lists were registered for each patient. Trade name, generic name, administration form, strength and dosing were registered for all drugs. Over-the-counter drugs were only registered if they were prescribed by a doctor.

Finally, the drugs were classified according to the Anatomical Therapeutic Chemical system. ${ }^{17}$

For each patient, drug lists from the GP and/or the home care services/the nursing home were compared with the drug information available at admission. Discrepancies revealed were linked to the drug involved and registered in a separate form. Since the hospital record list could be compared with information both from the GP and from the home care services or the nursing home, there could be up to two discrepancies per drug. None of the patients had information both from the home care services and from the nursing home. Discrepancies were either classified as 'omission of drug' (ie, the drug was lacking in one of the lists) or 'difference in dosing' (ie, differences with regard to administration form, strength or dosage).

An expert panel consisting of four persons (clinical pharmacologist, geriatrician, physician from tTo he specific ward and clinical pharmacist) rated the discrepancies for their potential clinical impact. Assessment of the discrepancies was performed using a previously published method where the discrepancies were rated in three classes according to whether they had potential to cause minimal, moderate or severe discomfort or harm to the patient. ${ }^{2}$ This rating scale developed by Cornish et al, has also been used in several other studies. ${ }^{518-21}$ In addition, a fourth class, denoted non-classifiable, was added. When evaluating the effect of each discrepancy, the expert panel took into account that the error was carried forward for an average hospital stay in the same department, which was 2-3 days for gastrointestinal surgery and internal medicine wards and 4-7 days for the geriatric ward. The evaluation also took the patients' diagnoses and clinical status, as described in the electronic patient record into account. Each member of the panel first rated the discrepancies alone before the cases were discussed in a meeting. Disagreements between the panel members were solved by discussion, and consensus was reached in all cases. The expert group started its work by evaluation of 10 pilot cases collected in the same way as in the main study. This was done to give the expert panel a common understanding of the classification system and the working model.

Statistical comparisons of number of drugs and total number of discrepancies between different groups of patients were performed using Mann-Whitney U test. Comparisons of number of discrepancies from different sources of information were performed using an independent sample Kruskal-Wallis test (SPSS V.19; SPSS). p Values $<0.05$ were considered statistically significant.

\section{RESULTS}

A total of 168 patients were included in the study, 56 from the gastrointestinal surgery wards, 51 from the general internal medicine wards and 61 from the geriatric ward. According to information available at admission, there were a total of 901 prescriptions, that is, a mean of 5.4 (range $0-19$ ) prescriptions per patient. However, when information from all sources was combined, the total number of prescriptions was 1176 , that is, a mean of 7.0 (range $0-24$ ) prescriptions per patient. Twelve patients $(7 \%)$ did not use any drugs at all according to all sources of information. Characteristics of the patient population and details about the number of drugs prescribed are presented in table 1 .

There was no significant difference in the total number of drugs prescribed between male and female patients (mean 7.0; range $0-17$ vs mean 7.1 ; range 0-24; $\mathrm{p}=0.956)$.

Patients below the age of 80 years had a mean number of 6.5 drugs prescribed (range 0-24) which was significantly lower than the mean number of 7.7 drugs (range $0-19)$ prescribed to patients 80 years or older $(\mathrm{p}=0.034)$.

Patients who administered their own drugs had a mean number of 5.9 drugs prescribed (range $0-17$ ), which was significantly lower than the mean number of 8.9 drugs (range 0-24) prescribed to patients with help from the home care services or a nursing home $(\mathrm{p}<0.001)$.

Of the 168 patients in the study, 139 (83\%) had at least one discrepancy when comparing the information 
Table 1 Characteristics of the 168 patients included in the study and number of drugs prescribed according to the various sources of information

\begin{tabular}{|c|c|c|c|c|}
\hline & Gastrointestinal surgery & Internal medicine & Geriatrics & Total \\
\hline Number of patients & 56 & 51 & 61 & 168 \\
\hline Mean age, years (range) & $62(22-91)$ & 78 (45-92) & $83(65-96)$ & $74(22-96)$ \\
\hline Female gender, $\mathrm{n}(\%)$ & $28(50.0)$ & $29(56.9)$ & $44(72.1)$ & $101(60.1)$ \\
\hline $\begin{array}{l}\text { Living in their own home without home care } \\
\text { services, } \mathrm{n}(\%)^{\star}\end{array}$ & $47(83.9)$ & $32(62.7)$ & $22(36.1)$ & $101(60.1)$ \\
\hline $\begin{array}{l}\text { Living in their own home with home care } \\
\text { services, } \mathrm{n}(\%)^{*}\end{array}$ & $7(12.5)$ & $15(29.4)$ & $31(50.8)$ & $53(31.5)$ \\
\hline Living in a nursing home, $\mathrm{n}(\%)^{\star}$ & $2(3.6)$ & $4(7.8)$ & $8(13.1)$ & $14(8.3)$ \\
\hline $\begin{array}{l}\text { Number of patients with no drugs according to } \\
\text { all sources, } \mathrm{n}(\%)\end{array}$ & $9(16.1)$ & $0(0)$ & $3(4.9)$ & $12(7.1)$ \\
\hline \multicolumn{5}{|c|}{ Mean number of drugs per patient (range) according to information from the various sources $\dagger$} \\
\hline Information available at admission to hospital & $3.1(0-11)$ & $8.7(3-19)$ & $4.7(0-17)$ & $5.4(0-19)$ \\
\hline Information from the general practitioner $\ddagger$ & $3.9(0-12)$ & $8.4(3-16)$ & $4.6(0-15)$ & $5.2(0-16)$ \\
\hline $\begin{array}{l}\text { Information from the home care services/ } \\
\text { nursing home§ }\end{array}$ & $8.5(5-14)$ & $8.5(4-16)$ & $6.0(0-15)$ & $7.2(0-16)$ \\
\hline All available sources combined & $4.8(0-14)$ & $10.4(5-24)$ & $6.2(0-20)$ & $7.0(0-24)$ \\
\hline
\end{tabular}

*Percentages may not total 100 due to rounding.

†All patients had information from at least one supplementary source (ie, general practitioner and/or home care services/nursing home). łInformation available for 54 gastrointestinal surgery patients, 49 internal medicine patients and 53 geriatric patients.

§Information available for 7 gastrointestinal surgery patients, 19 internal medicine patients and 31 geriatric patients.

available at admission with the other available sources of information. In the gastrointestinal surgery wards, the number of patients with discrepancies was $43(77 \%)$; in the internal medicine wards, the number was $47(92 \%)$ and in the geriatric ward, the number was 49 (80\%). Among these patients, there was a range from 1 to 32 discrepancies.

The number of discrepancies when comparing the drug information available at admission to the different sources of information is presented in table 2.

In total there were 697 discrepancies among all patients. Difference in dosing counted for 195 discrepancies $(28 \%)$, whereas omission of drug was the cause of the remaining 502 discrepancies $(72 \%)$. Of the omitted drugs, $404(80 \%)$ were missing in the drug list recorded at admission. In the remaining 98 cases $(20 \%)$, it had been stated in the hospital record that

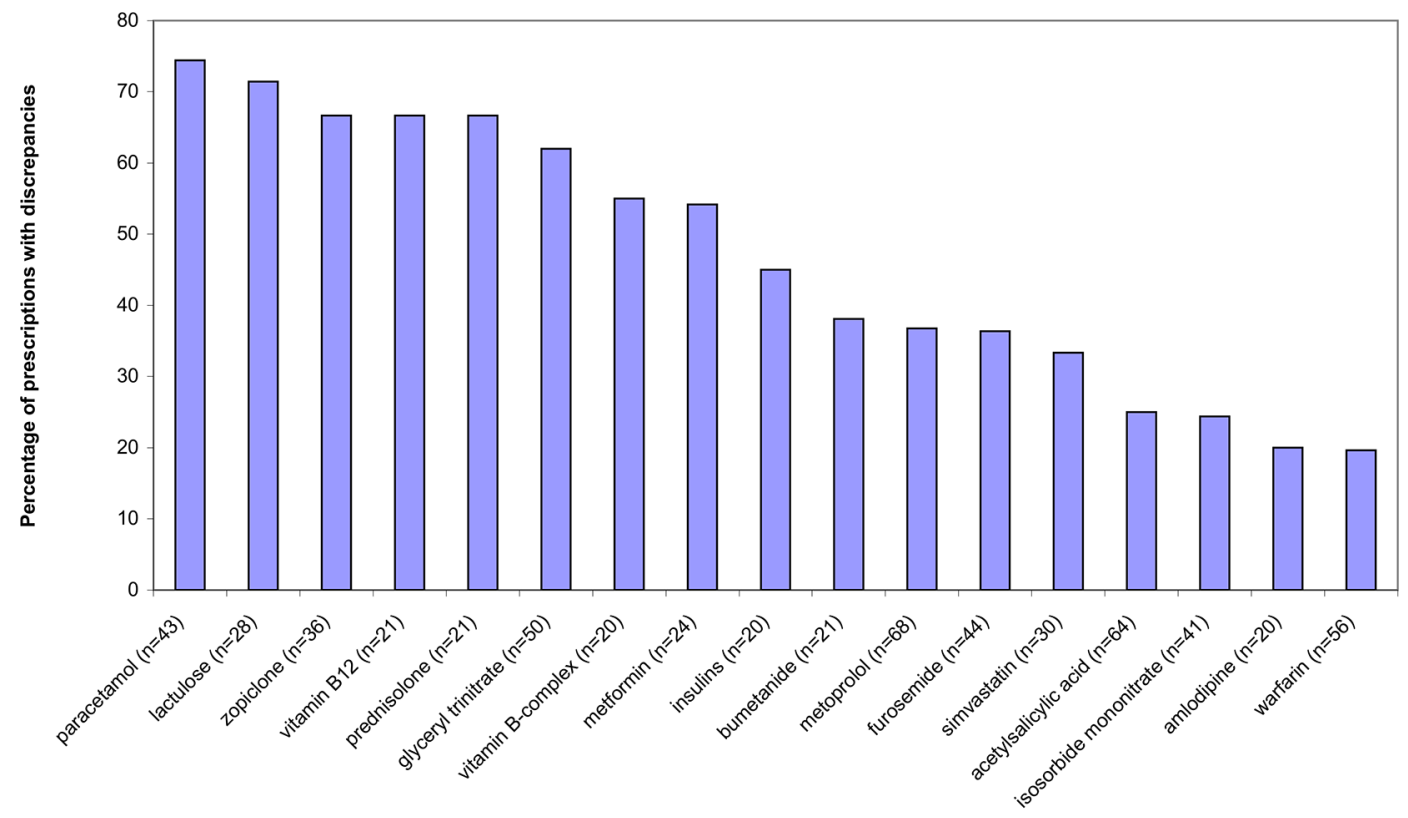

Drugs prescribed for 20 patients or more ( $n=$ number of patients that the drug has been prescribed for)

Figure 2 Drugs prescribed for 20 patients or more sorted by the percentage of prescriptions with discrepancies. 
Table 2 Mean number of discrepancies (range) per patient when comparing the drug information available at admission to information from the various sources*

\begin{tabular}{|c|c|c|c|c|}
\hline & $\begin{array}{l}\text { Gastrointestinal } \\
\text { surgery }\end{array}$ & $\begin{array}{l}\text { Internal } \\
\text { medicine }\end{array}$ & Geriatrics & Total \\
\hline Information from the general practitionert & $3.0(0-11)$ & $4.1(0-18)$ & $2.6(0-17)$ & $3.2(0-18)$ \\
\hline All available sources combined§ & $3.4(0-15)$ & $5.4(0-32)$ & $3.7(0-24)$ & $4.1(0-32)$ \\
\hline
\end{tabular}

*All patients had information from at least one supplementary source (ie, general practitioner and/or home care services/nursing home). †Information available for 54 gastrointestinal surgery patients, 49 internal medicine patients and 53 geriatric patients. łInformation available for 7 gastrointestinal surgery patients, 19 internal medicine patients and 31 geriatric patients. $\S U$ to two discrepancies per drug.

the patient used a drug at admission, but this drug was not listed in any other source of information.

The distribution of patients according to their total number of discrepancies for each of the three departments is shown in figure 1.

Among the 17 drugs prescribed for 20 patients or more, paracetamol and lactulose had the highest percentage of prescriptions with discrepancies, with $74 \%$ and $70 \%$, respectively. The percentage of discrepancies related to all the prescriptions of the same drug is presented in figure 2 .

There were no significant differences in the number of discrepancies between male and female patients (mean 4.1; range 0-32 vs mean 4.2; range $0-22 ; \mathrm{p}=0.772$ ) or between patients below and above the age of 80 years (mean 3.7; range 0-32 vs mean 4.7; range 0-22; $\mathrm{p}=0.056$ ). Patients who administered their own drugs had a mean number of 2.8 discrepancies (range $0-11$ ), as compared with 6.2 discrepancies (range $0-32$ ) in patients whose drugs were administered by the home care services or lived in a nursing home $(\mathrm{p}<0.001)$.

When correcting for the number of drugs prescribed by calculating number of discrepancies per prescribed drug (the number of discrepancies in a patient divided by the number of drugs prescribed to the same patient), there was no statistically significant difference between any of the groups compared. Male and female patients had means of 0.50 and 0.49 , respectively $(\mathrm{p}=0.502)$, whereas patients below and above the age of 80 years had means of 0.53 and 0.48 , respectively $(\mathrm{p}=0.135)$. Patients who were prescribed less than five drugs had a mean of 0.53 , as compared with 0.48 in patients that were prescribed five drugs or more $(\mathrm{p}=0.465)$. Patients who administered their own drugs had a mean of 0.47 , as compared with 0.54 in patients that had their drugs administered by the home care services or lived in a nursing home $(\mathrm{p}=0.235)$.

More than half of the discrepancies $(381 / 697 ; 55 \%)$ were classified as having the potential to cause only minimal harm or discomfort to the patients. In addition, $33 \%(231 / 697)$ had the potential to cause moderate harm or discomfort, $9 \%(62 / 697)$ had the potential to cause severe harm or discomfort, whereas $3 \%(23 / 697)$ were considered non-classifiable. The number of discrepancies classified according to their potential to cause harm or discomfort to the patient within each group is presented in table 3 .

Among the 168 patients included in the study, 28 $(17 \%)$ had a total of 62 discrepancies with a potential to cause severe harm or discomfort (class 3), with a range from 1 to 13 severe discrepancies per patient. Omission of drug counted for 58 of the severe discrepancies, whereas difference in dosing was the cause of the remaining 4 .

Thirty-two different drugs were involved in these severe discrepancies. The drugs/drug groups most often implicated were antithrombotic agents $(n=8)$, insulin $(n=7)$, corticosteroids for systemic use $(n=6)$, oral blood glucose lowering drugs $(n=6)$ and beta blockers $(n=5)$.

Table 4 presents some representative case histories with one or more discrepancies classified as severe.

Table 3 Number of discrepancies classified according to their potential to cause harm or discomfort to the patient

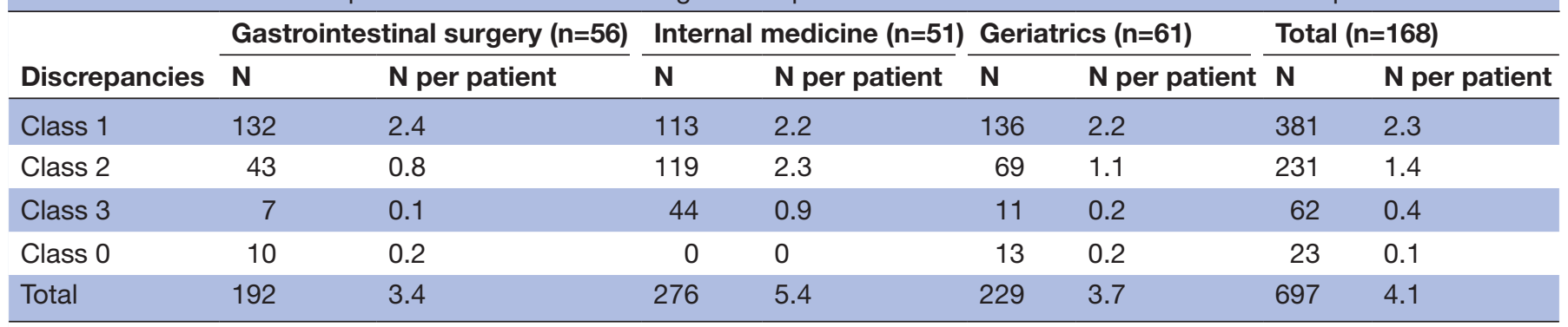

Class 1: potential to cause minimal harm or discomfort to the patient, class 2: potential to cause moderate harm or discomfort to the patient, class 3: potential to cause severe harm or discomfort to the patient, class 0: non-classifiable. 
Table 4 Examples of patients with discrepancies considered having the potential to cause severe harm or discomfort.

\section{Patient Case}

Class 3 discrepancies

A An 82-year-old man with severe dementia, atrial flutter, diabetes mellitus type II and metastatic prostate cancer. He was living in a nursing home and was admitted to the geriatric ward because of acute delirium. The hospital record at admission did not mention any drugs or the prostate cancer diagnosis. However, according to the nursing home notes, the patient was using methylprednisolone $8 \mathrm{mg}$ and morphine slow release $60 \mathrm{mg}$ daily in addition to glipizide, paracetamol and lactulose.

B A 75-year-old woman with heart failure and previously myocardial infarction and stroke. She was living in a nursing home and was admitted to the department of internal medicine because of seizures. Venlafaxine and fluoxetine were listed in the hospital record at admission. However, according to the nursing home notes, she was using ramipril $5 \mathrm{mg}$ daily for her heart failure in addition to seven other drugs.

A $63-y e a r-o l d$ woman with chronic obstructive pulmonary disease (COPD). She was living
in her home, administering her own drugs and was admitted to the gastrointestinal surgery
ward with acute abdominal pain. The hospital record at admission listed use of salbutamol,
methylprednisolone
ipratropium bromide and acetylcysteine. According to the general practitioner she was
currently also prescribed methylprednisolone $15 \mathrm{mg}$ and theophylline for her COPD in
addition to antiplatelet treatment with acetylsalicylic acid.
An 86-year-old woman with hypothyroidism and several transient ischaemic attacks was
admitted to the geriatric ward because of general functional deterioration, headache and
dizziness. She was living in her home with help from the home care services. The hospital
record at admission did not list any drugs, and the hypothyroidism was not stated. Both
the general practitioner and the home care services listed dipyridamole, acetylsalicylic acid,
hydrochlorothiazide, fluoxetine and levothyroxine.

\section{DISCUSSION}

The principal finding in the present study is that $83 \%$ of the patients had one or more discrepancies in their drug history at admission to hospital. This number is higher than in most other studies, although it also varies considerably between previous studies. A review from 2005 found errors in $10 \%-67 \%$ of the cases, ${ }^{4}$ and newer studies from Sweden, Norway and USA show error rates of $47 \%, 50 \%$ and $51 \%$, respectively. ${ }^{3516}$ There is no indication that the higher error rates in our study are caused by stricter definitions in other studies. However, most other studies compare the different sources of information to the hospital drug chart and not the drug information available at admission to hospital. To the best of our knowledge, only two previous studies ${ }^{22}$ has compared the drug information available at admission to other sources of drug information. We believe it is more appropriate to evaluate drug information in the admission record than in the hospital drug chart because changes might take place on the discretion of the physician in charge before the drug list is transferred from the admission record to the drug chart. On the other hand, information from the patients themselves was not included in our analysis, and this might in fact have led to a lower error rate.

Patients admitted to the gastrointestinal surgery wards were younger, had less assistance from the home care services and were less often living in nursing homes than the patients from internal medicine and geriatric wards. One could therefore have expected fewer patients with discrepancies in the gastrointestinal surgery wards than in both the internal medicine and the geriatric wards.
However, this was not the case, as $77 \%$ of the patients in the gastrointestinal surgery and $80 \%$ in the geriatric wards had at least one discrepancy, compared with as much as $92 \%$ of the internal medicine patients. This indicates that type of ward (as a rough indicator of the cause of admittance) does not seem to be an important factor for predicting the risk of discrepancies in drug history of a patient.

Potential to harm or cause discomfort to the patient could have been underestimated in this study, since the effect of each discrepancy took into account that the mistake was carried forward for just an average hospital stay in the actual department, which was 2-3 days for gastrointestinal surgery and internal medicine wards and 4-7 days for the geriatric ward. We know, both from the literature $^{1423-26}$ and from our own unpublished data, that erroneous drug lists with consequent incorrect use of drugs often follow the patients out of the hospital and will not be corrected for months or even years. For many of the discrepancies, the potential to cause harm or discomfort to the patient will rise substantially with time. We chose this time perspective after thorough discussion among the members of the expert group to avoid overestimating the potential to cause harm or discomfort.

We found that patients with home care services or living in a nursing home had more discrepancies than patients that were handling their drugs themselves, although this difference disappeared after correction for the number of drugs prescribed. In contrast, a Swedish study from $2012^{3}$ found that patients living in their own home without any care services had an increased risk of medication history 
errors. These differences might be caused by the fact that the healthcare regulation and information systems in Sweden and Norway are somewhat different. In Sweden, healthcare professionals in primary and secondary care in some cases have access to each other's electronic records, and there is one common record for the primary care sector. In Norway, there are several patient record systems both within primary care and within secondary care. These systems do not communicate, and health professionals from primary and secondary care or even from different hospitals do not have access to each other's patient records. This non-transparency and the complicated systems for transfer of information might also lead to a higher error rate, especially for patients receiving home care services or living in a nursing home.

The number of discrepancies per drug prescribed was not significantly higher for patients using a high number of drugs than for those using fewer drugs. As opposed to the Swedish study, ${ }^{3}$ the proportion of drugs associated with a discrepancy was similar for patients with five or more drugs and for those with less than five drugs. In our study, the number of discrepancies per patient seems to increase in parallel with the number of drugs prescribed.

This study has several limitations. First, there is no 'golden standard' regarding the information of which drugs the patient actually has been taking the last days before admission. In fact, none of the lists we have consulted are necessarily 'correct' (depending on the definition of the word 'correct'-is it the drugs the patient has taken or the drugs the patient should have been taking). Although we do not know in detail which drugs and dosages the patient has actually been taking, most probably no one else does either (with the possible exception of the patient himself/herself), as there almost always will be some degree of non-adherence and in some case also overadherence. Information from the patients themselves was collected in our study, but it was not integrated with the rest of the data because most patients had very incomplete knowledge of which drugs they were using. For example, they could state that they were taking a white tablet 'for their heart' twice daily, but without knowing the specific name of the drug. This information could be important in the clinical setting, but for the purpose of our study, it was in most such cases not possible to decide whether it should be classified as a discrepancy or not related to the information in the hospital record. In a Danish study from 2003, Andersen et $a l^{13}$ concluded that second interviews and GP lists reveal extra information in two-thirds of cases, but they did not specify the relative importance of these two sources. However, in the clinical setting, both procedures should be routinely performed to compile a more comprehensive basis for drug prescribing.

Second, the harm assessment was made for each drug discrepancy separately rather than by performing one common harm rating for all discrepancies found for a patient, which it can be argued would have been more clinically relevant. Another factor regarding the harm assessment is that the scale employed did not take into account that a discrepancy potentially could have a positive effect for the patient, such as the omission of an obviously inappropriate drug.

On the other hand, this study also has some strengths. Among these is the fact that patients were included from three different types of wards in two hospitals, thereby including both surgical and medical causes of admittance. Moreover, the patients had a broad age range compared with most other studies. ${ }^{27}$ Thus, our results could be considered valid for a variety of patient populations and not just for older patients in internal medicine wards, who have been included in most previous studies. Consequently, we consider that medication reconciliation should have high priority regardless of the patient's age or cause of admittance.

Another strength is the use of a multidisciplinary expert group and the inclusion of pilot cases to enhance the understanding of the severity score classification and increase the conformity of the evaluations in the group. Moreover, all discrepancies were discussed in the group, irrespective of whether the members had made identical classifications or not.

In conclusion, our study shows that a high proportion of patients admitted to hospital have discrepancies in their drug histories, and it supports the importance of collecting drug information from all available sources. Furthermore, we found no significant differences in the number of discrepancies when comparing different hospitals, hospital wards, genders, ages or levels of care. We therefore conclude that medication reconciliation should be considered an important potential quality improvement method that preferably should be performed for all patients admitted to hospital, even for patients receiving assistance from home care services or living in a nursing home.

\section{Author affiliations}

${ }^{1}$ Department of Clinical and Molecular Medicine, Norwegian University of Science and Technology, Trondheim, Norway

${ }^{2}$ Clinical Pharmacy Services, Central Norway Hospital Pharmacy Trust, Trondheim, Norway

${ }^{3}$ Department of Geriatrics, St Olav's University Hospital, Trondheim, Norway ${ }^{4}$ Department of Neuroscience, Norwegian University of Science and Technology, Trondheim, Norway

${ }^{5}$ Department of Clinical Pharmacology, St Olav's University Hospital, Trondheim, Norway

${ }^{6}$ Clinical Pharmacy Services, Ålesund Hospital Pharmacy, Ålesund, Norway ${ }^{7}$ Department of Internal Medicine, Ålesund Hospital, Ålesund, Norway

${ }^{8}$ Faculty of Medicine and Health Sciences, Norwegian University of Science and Technology, Trondheim, Norway

${ }^{9}$ Department of Gastrointestinal Surgery, St Olav's University Hospital, Trondheim, Norway

Acknowledgements We would like to thank the staff at the gastrointestinal surgery wards at St Olav's University Hospital in Trondheim, the internal medicine wards at Ålesund Hospital in Ålesund and the geriatric ward at St Olav's University Hospital for their collaboration. We are grateful to the Liaison Committee between 
the Central Norway Regional Health Authority and the Norwegian University of Science and Technology and to the Central Norway Hospital Pharmacy Trust for funding the study.

Contributors JKS planned the study and collected and analysed the data, did the calculations and wrote the first version of the manuscript. OSI planned the study, analysed the data and contributed to the final version of the manuscript. TCM planned the study, collected and analysed parts of the data and contributed to the final version of the manuscript. RH collected and analysed parts of the data and contributed to the final version of the manuscript. TH, PEU and PTV analysed parts of the data and contributed to the final version of the manuscript. OSp planned the study, analysed the data, did the calculations and contributed to the final version of the manuscript.

Funding This work was supported by the Liaison Committee between the Central Norway Regional Health Authority and the Norwegian University of Science and Technology.

Competing interests None declared.

Provenance and peer review Not commissioned; externally peer reviewed.

Data sharing statement There is no more available data from this study.

Open Access This is an Open Access article distributed in accordance with the Creative Commons Attribution Non Commercial (CC BY-NC 4.0) license, which permits others to distribute, remix, adapt, build upon this work non-commercially, and license their derivative works on different terms, provided the original work is properly cited and the use is non-commercial. See: http://creativecommons.org/ licenses/by-nc/4.0/

(c) Article author(s) (or their employer(s) unless otherwise stated in the text of the article) 2017. All rights reserved. No commercial use is permitted unless otherwise expressly granted.

\section{REFERENCES}

1. Chhabra PT, Rattinger GB, Dutcher SK, et al. Medication reconciliation during the transition to and from long-term care settings: a systematic review. Res Social Adm Pharm 2012;8:60-75.

2. Cornish PL, Knowles SR, Marchesano R, et al. Unintended medication discrepancies at the time of hospital admission. Arch Intern Med 2005; 165:424-9.

3. Hellström LM, Bondesson $\AA$, Höglund P, et al. Errors in medication history at hospital admission: prevalence and predicting factors. BMC Clin Pharmacol 2012;12:9.

4. Tam VC, Knowles SR, Cornish PL, et al. Frequency, type and clinical importance of medication history errors at admission to hospital: a systematic review. CMAJ 2005;173:510-5.

5. Gjerde AM, Aa E, Sund JK, et al. Medication reconciliation of patients with hip fracture by clinical pharmacists Eur J Hosp Pharm 2016;23:166-70.

6. Gleason KM, McDaniel MR, Feinglass J, et al. Results of the Medications at Transitions and Clinical Handoffs (MATCH) study: an analysis of medication reconciliation errors and risk factors at hospital admission. J Gen Intern Med 2010;25:441-7.

7. Pippins JR, Gandhi TK, Hamann C, et al. Classifying and predicting errors of inpatient medication reconciliation. J Gen Intern Med 2008;23:1414-22.

8. . IHI IfHI. Medication reconciliation review. USA: System LMMH, Eau Claire W, 2014.
9. NICE. Technical patient safety solutions for medicines reconciliation on admission of adults to hospital, 2014.

10. Reeder TA, Mutnick A. Pharmacist- versus physician-obtained medication histories. Am J Health Syst Pharm 2008;65:857-60.

11. De Winter S, Spriet I, Indevuyst C, et al. Pharmacist- versus physician-acquired medication history: a prospective study at the emergency department. Qual Saf Health Care 2010;19:371-5.

12. Unroe KT, Pfeiffenberger T, Riegelhaupt S, et al. Inpatient medication reconciliation at admission and discharge: a retrospective cohort study of age and other risk factors for medication discrepancies. Am $J$ Geriatr Pharmacother 2010;8:115-26.

13. Andersen SE, Pedersen AB, Bach KF. Medication history on internal medicine wards: assessment of extra information collected from second drug interviews and GP lists. Pharmacoepidemiol Drug Saf 2003;12:491-8.

14. Climente-Martí M, García-Mañón ER, Artero-Mora A, et al. Potential risk of medication discrepancies and reconciliation errors at admission and discharge from an inpatient medical service. Ann Pharmacother 2010;44:1747-54.

15. Picone DM, Titler MG, Dochterman J, et al. Predictors of medication errors among elderly hospitalized patients. Am J Med Qual 2008;23:115-27.

16. Kripalani S, Roumie CL, Dalal AK, et al. Effect of a pharmacist intervention on clinically important medication errors after hospital discharge: a randomized trial. Ann Intern Med 2012;157:1-10.

17. WHO. The anatomical terapeutic chemical classification system with defined daily doses (ATC/DDD), 2003.

18. Arora V, Kao J, Lovinger D, et al. Medication discrepancies in resident sign-outs and their potential to harm. J Gen Intern Med 2007;22:1751-5.

19. Grimes TC, Duggan CA, Delaney TP, et al. Medication details documented on hospital discharge: cross-sectional observational study of factors associated with medication non-reconciliation. $\mathrm{Br} \mathrm{J}$ Clin Pharmacol 2011;71:449-57.

20. Kalb K, Shalansky S, Legal M, et al. Unintended medication discrepancies associated with reliance on prescription databases for medication reconciliation on admission to a general medical ward. Can J Hosp Pharm 2009;62:284-9.

21. Wekre LJ, Spigset O, Sletvold O, et al. Multidose drug dispensing and discrepancies between medication records. Qual Saf Health Care 2010;19:e42.

22. Steurbaut $\mathrm{S}$, Leemans L, Leysen $\mathrm{T}$, et al. Medication history reconciliation by clinical pharmacists in elderly inpatients admitted from home or a nursing home. Ann Pharmacother 2010;44:1596-603.

23. Bergkvist $A$, Midlöv $P$, Höglund $P$, et al. Improved quality in the hospital discharge summary reduces medication errors-LIMM: Landskrona Integrated Medicines Management. Eur J Clin Pharmacol 2009;65:1037-46.

24. Hellström LM, Bondesson A, Höglund $P$, et al. Impact of the Lund Integrated Medicines Management (LIMM) model on medication appropriateness and drug-related hospital revisits. Eur J Clin Pharmacol 2011;67:741-52.

25. Midlöv P, Deierborg E, Holmdahl L, et al. Clinical outcomes from the use of medication report when elderly patients are discharged from hospital. Pharm World Sci 2008;30:840-5.

26. Midlöv $\mathrm{P}$, Holmdahl L, Eriksson T, et al. Medication report reduces number of medication errors when elderly patients are discharged from hospital. Pharm World Sci 2008;30:92-8.

27. Mueller SK, Sponsler KC, Kripalani S, et al. Hospital-based medication reconciliation practices: a systematic review. Arch Intern Med 2012;172:1057-69. 